\title{
BAJO EL PESO DEL PREJUICIO. LAS CONCEPTUALIZACIONES DE POLONIA Y MÉXICO A TRAVÉS DE LOS DOCUMENTOS DIPLOMÁTICOS MEXICANOS A COMIENZOS DE LAS RELACIONES OFICIALES
}

\author{
Edyta Kwiatkowska-Faryś \\ Universidad Adam Mickiewicz de Poznań \\ https://doi.org/10.18778/8220-195-6.33
}

\section{Resumen}

Las observaciones de los diplomáticos mexicanos en la II República de Polonia testimonian la evolución de su concepto de Polonia como nación. Desde la perspectiva de la lingüística cultural, que toma en consideración no solo la realidad objetiva, sino también las experiencias y valores, se pretende observar los factores que portan la disensión en las opiniones del servicio exterior mexicano. El corpus proporciona datos para poder extraer conclusiones acerca de la imagen de Polonia que se traduce en un estereotipo, gravado con experiencias negativas.

Palabras clave: lingüística cultural, estereotipo, imagen lingüística-cultural, relaciones mexicano-polacas, conceptualización. 


\section{1.}

\section{Presentación y objetivo}

El intento del acercamiento oficial de Polonia y México tuvo lugar tras la reaparición de Polonia en el mapa político del mundo, estableciéndose finalmente la relación diplomática de la II Rzeczpospolita [II República de Polonia] y el México posrevolucionario en la segunda década del siglo XX $X^{1}$. El objetivo del presente análisis es aproximar la imagen lingüística y cultural de Polonia en el discurso diplomático mexicano en las primeras décadas de las relaciones oficiales. Es una reconstrucción etnolingüística de la actitud de los mexicanos -representantes de un Estado de diferentes experiencias políticas, sociales y culturales- hacia Polonia y polacos como nación.

El análisis se nutre de los textos que documentan las relaciones polaco-mexicanas, por lo tanto nos encontraremos, a la vez, con un conjunto de valores y experiencias contrapuestas, expresadas y conceptualizadas por la parte polaca. Tales muestras reflejan la imagen de México entre los polacos: en el presente trabajo las comentaremos brevemente para acentuar las circunstancias que acompañaron al entablamiento de las relaciones oficiales.

No cabe duda que la cultura popular y los heteroestereotipos comunes en toda Europa a principio del siglo XX proporcionaron el fundamento para la percepción colectiva del país azteca entre los polacos. En cambio, para el México de Carranza y Obregón Polonia era una nación desconocida. Analizaremos en qué grado el discurso diplomático que documenta la recién entablada relación política bilateral contribuye a la formación del concepto de Polonia en México y de México en Polonia.

1 En 1921 México recibió solicitud de reconocimiento de Polonia, y otros cuatro países, según podemos leer en el informe del presidente Álvaro Obregón ante el Congreso (Informe, 2006), considerando esta fecha la del establecimiento de las relaciones formales (Relaciones, 1989: 11). En otra publicación se consigna que tales relaciones formales se establecieron en los primeros meses de 1928, tras haber renovado México su propuesta de entablar las "formales relaciones diplomáticas” (Recomendaciones, 2015: 13; Smolana, 2018: 46). 


\section{Marco histórico}

La distancia, el mutuo desconocimiento y un cierto desinterés aportan a que la percepción del otro país se encamine por los estereotipos. El fin de la Primera Guerra Mundial en Europa posibilitó la reaparición de Polonia. En el mismo año, 1918, en México terminó la Revolución, lo que trajo un nuevo orden político en este país. El periodo posterior a la Primera Guerra Mundial, tanto en Polonia, como en México, garantizó de alguna manera la posibilidad de normalización de la situación política en ambos países. A pesar de las mutuas miradas, en buena parte prejuiciadas, los dos países tenían no poco en común: uno, recién recuperada su independencia y el otro recién salido de una revolución, enfrentaban el reto de reconstruir el país.

No obstante, con el paso de los años, se pusieron de manifiesto los valores contrapuestos defendidos por cada país ${ }^{2}$. También influye en el distanciamiento político el hecho de escaso flujo migratorio del territorio polaco a México ${ }^{3}$. De hecho, no hubo ningún significativo vínculo previo, ni una experiencia social o cultural compartida, para que se puedan abstraer de ellas los valores o rasgos del otro más fundamentados en la realidad.

2 Prueba de eso es en la participación de ambos gobiernos en la Sociedad de Naciones: en el caso de la invasión italiana a Abisinia, en 1935, México la condenó y se negó a reconocer la anexión de este país africano a Italia. Polonia, en cambio, mantenía buenas relaciones con el gobierno de Mussolini. En el caso de la guerra civil española, mientras México prestó auxilio a los republicanos derrotados y exiliados, Polonia, por el contrario, reprimía a sus ciudadanos que lucharon a favor de la República y en algunos casos llegó a privarlos de la nacionalidad (Łepkowski, 1986: 392-393).

3 Aunque hubo personas que inmigraron de Polonia a México, en el periodo de entreguerras se tuvo un censo de 7500 personas (Jacórzyński, Kozłowski, 2015: 24), conviene aclarar que muchos de estos migrantes pretendían llegar a Estados Unidos. 


\section{Aspectos metodológicos y fuentes}

$\mathrm{Al}$ aplicar las herramientas de la lingüística cultural nos interesamos no tanto por cómo hablan las personas sobre la realidad objetiva, sino por cómo hablan sobre el mundo que ellos mismos perciben. Por lo tanto, en el estudio recurrimos a la idea de la conceptualización, entendida como una imagen del fenómeno investigado y partimos de la básica afirmación: conceptualizar es encapsular las intuiciones cognitivas en un concepto.

El hablante, desde su cultura y subjetividad, categoriza la realidad. No es, sin embargo, un clásico triangulo semántico de Ogden y Richards, sino un constructo donde la relación de la imagen lingüística y cultural del mundo con el mundo real es solamente tentativa (Głaz, 2017).

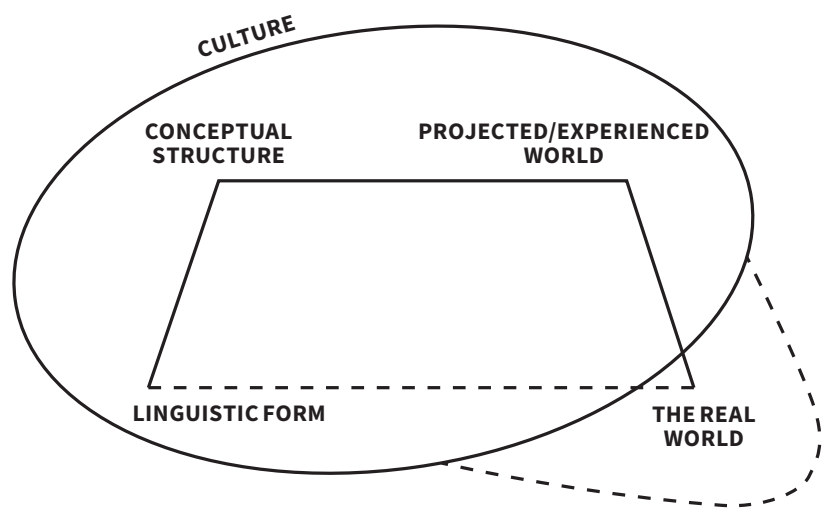

Figura 1. Trapecio semiótico con el componente cultural (Głaz, 2017)

En principio se trata de la percepción subjetiva de los emisores, inscrita en su propia experiencia cultural y sus valores (así como sus identidades). El análisis lingüístico-cultural de determinados conceptos permite ver qué elementos de la visión subjetiva influyeron en la imagen lingüística-cultural de dicho concepto.

El presente análisis, se sustenta en las propuestas metodológicas formuladas por Anusiewicz (1991) en su teoría cultural del lenguaje, por Bartmiński (1990) acerca de la imagen lingüística 
del mundo, y recientemente por Bartmiński y Chlebda (2013) con la imagen lingüística-cultural del mundo:

El 'concepto', que es el 'estereotipo', consiste en un conjunto de rasgos más amplio que una 'noción'; lo constituye no solamente un contenido cognoscitivo, sino también emotivo y pragmático, basado en una experiencia individual y social (Bartmiński, Chlebda, 2013: 71).

El corpus, reunido para este estudio, consta de los textos oficiales generados por el servicio exterior mexicano. Su selección se debe al criterio histórico: comprende documentos emitidos entre el año 1921 y $1945^{4}$. Constituyen el material de trabajo varios formatos diplomáticos de las primeras décadas de las relaciones diplomáticas: informes, oficios, cartas, memorándum, telegramas, boletines generados por el servicio exterior mexicano. El corpus por su naturaleza no es un conjunto completo, dado que a menudo no era posible acceder a ciertas partes del acervo, no todas las fuentes se consiguen en original, además algunas siguen clasificadas o varios expedientes no han sido íntegramente catalogados.

Los documentos fueron consultados tanto en forma de antologías de fuentes, como por medio de acceso directo al acervo histórico que conserva los documentos originales 5 .

4 El marco temporal comprendido entre el informe presidencial de Obregón sobre el reconocimiento de Polonia y la memoria para la Secretaria de Relaciones Exteriores sobre la colonia Santa Rosa, de diciembre 1945.

5 Se trata principalmente de la publicación del Archivo Histórico Diplomático Mexicano: Relaciones México Polonia 1921/1989. Cronología y documentos (1989). Los expedientes consultados se encuentran archivados en el Archivo Histórico Genaro Estrada en México (Archivo de Secretaría de relaciones Exteriores - AREM). 


\section{4.}

\section{Heteroestereotipos: Polonia demasiado contrarrevolucionaria, México demasiado revolucionario}

Las características que conlleva el concepto de Polonia y el concepto de México, difundidas en las primeras décadas del siglo XX, derivan de una serie de prejuicios resultantes de un profundo desconocimiento mutuo. Según Łepkowski (1980: 43), la actitud de la II República hacia el México revolucionario estuvo marcada por el estereotipo de la época. Para los polacos, México era un país misterioso de una civilización antigua, cristianizado pero inestable e inculto. Se percibía más bien como un estado de bandoleros y no como un exótico país pacífico. Pero, sobre todo, difundidas las decimonónicas tesis de Chevalier (1863), para Europa México era un país completamente inútil (Chevalier, 67; Łepkowski, 1980: 43). Además, en Polonia se popularizó bastante la opinión estadounidense acerca la situación política en México, según la cual el país generaba caos, desorden, crueldad, anticlericalismo y xenofobia (Łepkowski, 1980: 55-57).

En cambio, en México no se dieron antecedentes, ya que se desconocía Polonia casi por completo. Podemos suponer que la inicial curiosidad y buenos sentimientos de los mexicanos hacia Polonia tenían que ver con el hecho de que la veían como un estado débil que, al igual que México, había sido víctima de vecinos poderosos.

Sin embargo, mientras que la Polonia renacida en 1918, veía a Rusia bolchevique con desconfianza y resentimiento, el México revolucionario saludaba con entusiasmo a la Unión Soviética. Estos estereotipos y la nueva situación geopolítica mundial influyen en la consolidación de la valoración desfavorable en las relaciones bilaterales. 


\section{5.}

\section{Modeladores del concepto de Polonia}

Las observaciones diplomáticas constituyeron una especie de nueva fuente modeladora y modificadora del concepto de la otra nación. La mala opinión y desinterés del lado polaco respecto a México estaban correspondidos por la opinión de los diplomáticos mexicanos acerca de Polonia y su desorganización financiera, laboral, educativa, problemas con las minorías y con el aseguramiento de sus fronteras. Aunque tratamos de mantener un amplio panorama temporal, analizando los documentos de varias décadas, son particularmente destacables los informes de Rodolfo Nervo (enviadas en el período entre 1921 y 1932) y de Luciano Joublanc Rivas (del período de 1933 a 1939).

\section{1 .}

\section{Factores políticos}

En la primera etapa de las relaciones bilaterales encontramos varios oficios e informes de los diplomáticos mexicanos a sus superiores y a la inversa, en los cuales para apelar a Polonia se repite el término de "nación amiga", sobre todo en las cartas de Nervo (AREM: AEMF 110.2). El mismo representante no se abstiene de trasmitir a sus superiores las informaciones sobre los atributos negativos, en el contexto de las relaciones formales. Apunta a la desorganización protocolar e ignorancia, aunque lo considera "inevitable en un país que acaba de iniciarse en la vida internacional” (AREM: AEMF 79.15).

No obstante, las relaciones mexicano-polacas resultan poco fluidas y sin logros significativos para ambos países. La actitud polaca hacia México seguía, en general, poco amistosa ${ }^{6}$. Pero lo que causaba más rechazo y reforzó sin duda la imagen negativa de Polonia fue la larga militarización del país. Joublanc Rivas es-

6 México se quejaba por ejemplo, ya en los años 30, de la falta de reciprocidad en cuanto a las representaciones oficiales o de violaciones de la correspondencia diplomática por parte de Polonia (AREM: 438.1-0/510/1 Doc. n566, Varsovia, 15-10-35). 
cribe sobre "una oligarquía militar que encabeza el Mariscal José Pilsudski, héroe de la Independencia y amo de los destinos de la Republica" (AREM: III-1321-5 1. parte, f. s/n). En su descripción, Piłsudski

gobierna el país entre bastidores, pero con mano de hierro. Es una figura pintoresca, un hombre decidido a todo, que no titubeó ante el crimen y el latrocinio cuando se jugaban los destinos de su patria (AREM: III-1321-5 1. parte, f. s/n).

El ministro concluye que este régimen despótico "repugna al amor natural del todo mexicano por las libertades cívicas y las fórmulas democráticas que con tanto sacrificio y a costa de tantas vidas apenas vamos comenzando a implantar en nuestro país" (AREM: III-1321-5 1. parte, f. s/n). Asimismo advierte, en relación con el tema de militarismo, que:

Polonia está tan alejada de nosotros que esta desdichada situación no puede afectarnos, y lo único que debemos hacer, si deseamos mantener relaciones cordiales con su gobierno, será abstenernos de cualquier crítica que pudiera herir su susceptibilidad (AREM: III 1321-5 2. parte, f. s/n).

Polonia, según el cable del servicio exterior mexicano, se encontraba "ansiosa de figurar como gran Potencia europea y menospreciada a cada paso por las verdaderas grandes Potencias" (AREM: III-1321-5 1. parte, f. s/n). Joublanc Rivas observa que Polonia ha reaccionado con un "nacionalismo agudo que ciega a sus habitantes hasta hacerlos caer en extremos que dejan de ser respetables, por patrióticos, para caer en la comicidad y el ridículo" (AREM: III-1321-5 1. parte, f. s/n).

Cabe añadir que en su autoestereotipo Polonia, a pesar de la realidad política europea, se veía a sí mismo como "potencia media", con peso suficiente para intervenir en la Europa de la preguerra y que aspiraba a ciertos territorios coloniales, por ejemplo, en África (AREM: Doc. n 175, Varsovia, 7-03-35. Joublanc. III/ 510 (438-0) 1135-4). 


\section{2.}

\section{Factores económicos y culturales}

El comercio y la cultura pudieran haber elevado la calidad de la relación diplomática, y en consecuencia, mejorar la percepción colectiva de ambos países. Sin embargo, aunque Zygmunt Merdinger, diplomático polaco en México, admitiera en 1933 que "el intercambio entre Polonia y México reviste un carácter cada vez más amplio" (AREM III-137-13, f. s/n), los asuntos comerciales no dieron mayores resultados. Es más, los informes mexicanos transmiten una imagen de Polonia cada vez más desfavorable. Si bien el memorándum mexicano del mismo año (AREM III 2318-1, f. s/n.) expresa el deseo de "grandes proporciones del comercio en época no muy lejana", dado que "ambos países están en pleno desarrollo", en el mismo documento hace la observación general de "encontrarnos en una época tan desfavorable como la presente" (AREM III 2318-1, f. s/n.), que es una alusión a los incesantes inconvenientes que no permiten celebrar el tratado de comercio con Polonia.

Los expedientes reportan pequeños avances en asuntos del intercambio cultural, pero también relatan roces por la exhibición de películas y la difusión de publicaciones denigrables, como el film polaco La Paloma o la producción mexicana La sangre polonesa (Relaciones, 1989: 12-15). Al mismo tiempo Joublanc Rivas expresa en el informe su estima por la literatura polaca:

Las joyas literarias de Polonia, cuyos escritores descuellan especialmente en el campo teatral, están destinadas pues a ser conocidas en México únicamente por una pequeña élite, que podrá leerlas en traducciones francesas. El resto del público tendrá que conformarse con Sienkiewicz y Ossendowski (AREM: III-1321-5, 3. parte f. s/n).

Los diplomáticos se entusiasman con los músicos y compositores considerándolos el factor esencial de lo polaco, además libre del idioma, "uno de los más difíciles que hay actualmente en el mundo" según Joublanc Rivas, quien además apunta a los polacos como la "nación artística por excelencia" (Relaciones, 1989: 12-15). 
Independientemente del contacto oficial, en Polonia se extiende el concepto de México bárbaro, comunista, anticatólico y en crisis, manifestándose esta imagen sobre todo en la cultura popular. El reconocido escritor polaco Melchior Wańkowicz en 1927 publica en Varsovia un libro de reportajes titulado $W$ kościołach Meksyku [En las iglesias de México], fruto de su viaje y estancia de algunos meses en México. Logra acercar la temática mexicana al público polaco, pero al mismo tiempo refuerza la imagen del país bandido y cruelmente anticatólico.

En 1933, causando roces, aparecieron en la revista Polacy w Calym Świecie [Polacos en el Mundo Entero] varios artículos difamatorios, entre ellos el titulado: "Meksyk, żeby cię pochłonęło piekło na ziemi [México, que desaparezcas infierno sobre la tierra]", con una felicitación a la revista, firmada por Tadeusz Jarocki, agregado de la legación de Polonia en México (Stankiewicz, 1933).

En la misma década, repetidamente ${ }^{7}$, no se autorizó en Polonia el uso de la radio, solicitado por la legación mexicana, para hablar de un aniversario de la independencia de México (Relaciones, 1989: 25-31). En 1935 Joublanc Rivas comentará disgustado, en un cable a su cancillería, que en Polonia "se sigue el sistema de obtener el máximo de concesiones y ventajas con un mínimo de reciprocidad o nada, si es posible" (Relaciones, 1989: 25-31).

\section{3.}

\section{Factores espirituales}

Otra discrepancia cultural fue la cuestión religiosa, que dio lugar a la guerra cristera en México, lo que el gobierno polaco y la población, católicos, condenaban. Para los diplomáticos era difícil "encontrar un punto de contacto que haga posible el acercamiento y la simpatía" hacia la Polonia espiritual que notaban, en efecto, susceptible, acomplejada y fanática. Joublanc Rivas observa: "con excepción del idioma, estimo que las tendencias políticas y el fanatismo religioso (católico), tan característico de este país, son los mayores obstáculos para su acercamiento con el nuestro" (AREM: III-1321-5 1. parte, f. s/n).

7 Se hicieron estos intentos varias veces en el periodo de 1932 a 1939. 
El ministro aconseja en el mismo informe, que si hay interés en un acercamiento con Polonia:

...La mejor manera de conquistar la amistad y buena voluntad del pueblo y el gobierno polaco sería el demostrar, por todos los medios posibles, un sincero interés en su existencia como país independiente, en primer lugar; y después, tener siempre muy presente a Polonia en cualquier acto de carácter internacional al que sean invitadas las grandes Potencias; exteriorizar la admiración por sus grandes hombres (...); y evitar cuidadosamente cualquier pequeña omisión o crítica a la que una gran Potencia no concedería importancia, pero que Polonia, por sus circunstancias especiales, consideraría como deliberada ofensa, pues difícilmente habrá en estos momentos otro país en el mundo que tenga una susceptibilidad tan desarrollada (AREM: III 1321-5).

De hecho, en los próximos años, el tema "Polonia" se convertiría en el "problema polaco" (AREM: III726-7, f. s/n) y en los años cuarenta, para los mexicanos el rasgo más positivo de Polonia será su particular "nota exótica" (AREM: III-2413-16, f. s/n).

Del otro lado, en el mismo periodo de los años cuarenta, en la situación de otra guerra mundial y en vísperas del establecimiento de la colonia Santa Rosa ${ }^{8}$, el concepto polaco de México cambia radicalmente, dando paso a una imagen de "la tierra prometida" y "bendita tierra de paz" (AREM: III 639-10, f. s/n y AREM: III 2413-16, f. s/n.).

\section{6. \\ Conclusiones}

La conceptualización de una nación, influenciada por la subjetividad y la circunstancia de sus autores, repercute en la percepción colectiva de esta nación. Hoy en día, la relación bilateral

8 Más sobre la historia de Santa Rosa en Smolana, 2018: 97-120. 
México-Polonia tiene muchos espacios para desarrollarse. El reconocimiento y respeto son profundos y extensos. Hace un siglo, cuando los dos países, Polonia y México, empezaban a acomodarse en el teatro político internacional, las relaciones caían en la trampa de los mutuos estereotipos, cuyas consecuencias se observan en la cultura y en el lenguaje hasta la actualidad.

La consolidación de la progresiva estereotipización se hizo notar también en el lenguaje de los documentos analizados. Intentamos poner de relieve el fenómeno -hasta ahora no examinado- de una evolución cualitativa del concepto de Polonia. Su imagen, del país al principio tratado con simpatía, iba adquiriendo un aspecto desfavorable, un valor negativo, y se conceptualizó en el marco de lo vulnerable, fanático y exótico.

\section{Bibliografía}

\section{Acceso a fuentes}

Archivo Histórico Genaro Estrada en México: Archivo de Secretaría de relaciones Exteriores - AREM, México.

Relaciones México-Polonia, 1921-1989. Cronología y documentos (1989). México: Archivo Histórico Diplomático Mexicano.

\section{Estudios consultados}

Anusiewicz, J. (1991). "Kulturowa teoria języka. Zarys problematyki”, en: Anusiewicz, J. y J. Bartmiński (eds.), Język a Kultura, t. 1, 17-30. Wrocław: Wiedza o Kulturze.

Bartmiński J. (1990). "Punkt widzenia, perspektywa, językowy obraz świata” en Bartmiński J. (ed.), Językowy obraz świata, 109-127. Lublin: Wydawnictwo UMCS.

Bartmiński J., Chlebda W. (2013). "Problem konceptu bazowego i jego profilowania na przykładzie polskiego stereotypu Europy", Etnolingwistyka, 25: 69-95.

Cámara de Diputados (2006). Informe presidencial de Álvaro Obregón $1^{\circ}$ de septiembre de 1921. México: Cámara de Diputados, Dirección General de Investigación y Análisis. 
Głaz, A. (2017). “The linguistic sign: Metonymy and virtuality", Linguistik Online, 80 (1). DOI: <https://doi.org/10.13092/ lo.80.3565> [23.05.2018].

Jacórzyński, W.R. y Kozłowski, M.J. (2015). "Rostros de la presencia polaca en México: un vuelo a través de la historia”, Ulúa. Revista de Historia, Sociedad y Cultura, 26: 11-44.

Łepkowski, T. (1980). Polska-Meksyk 1918-1939. Wrocław: Ossolineum.

Łepkowski, T. (1986). Historia Meksyku. Wrocław: Ossolineum. Secretaría de Relaciones Exteriores (2015). Recomendaciones para el fortalecimiento de las relaciones México y Polonia. México: Secretaría de Relaciones Exteriores, Instituto Matías Romero.

Smolana, K. (2018). Polonia y México a lo largo de la historia: una perspectiva desde la misión diplomática polaca, trad. Edyta Kwiatkowska-Faryś. México: Secretaría de Relaciones Exteriores, Instituto Matías Romero.

Stankiewicz, J. (1933). "Meksyk, żeby cię pochłonęło piekło na ziemi", "Meksyk, kraina wiecznej rewolucji”, en Polacy w Całym Świecie: Czasopismo Ilustrowane Poświęcone Emigracji Polskiej, red. L. Nowak, Królewska Huta, 10-15 y 25-27.

Wańkowicz, M. (1927). W kościołach Meksyku. Warszawa: Towarzystwo Wydawnicze Rój. 